\title{
The combined use of Camellia sinensis and metronomic zoledronate in 4T1 mouse carcinoma against tumor growth and metastasis
}

\author{
KE-WANG LUO ${ }^{1,2}$, GRACE GAR-LEE YUE ${ }^{1,2}$, CHUN-HAY KO ${ }^{1,2}$, SI GAO ${ }^{1,2}$, JULIA KIN-MING LEE ${ }^{1,2}$, \\ GANG LI $^{3,4}$, KWOK-PUI FUNG ${ }^{1,2,4,5}$, PING-CHUNG LEUNG ${ }^{1,2}$ and CLARA BIK-SAN LAU ${ }^{1,2}$ \\ ${ }^{1}$ Institute of Chinese Medicine, ${ }^{2}$ State Key Laboratory of Phytochemistry and Plant Resources in West China, \\ ${ }^{3}$ Department of Orthopaedics and Traumatology, and ${ }^{4}$ School of Biomedical Sciences, The Chinese University \\ of Hong Kong; ${ }^{5}$ The Chinese University of Hong Kong-Zhejiang University Joint Laboratory and \\ Natural Products and Toxicology Research, Shatin, New Territories, Hong Kong, SAR, P.R. China
}

Received December 4, 2014; Accepted February 10, 2015

DOI: $10.3892 / o r .2015 .4001$

\begin{abstract}
In previous studies, we demonstrated that the green tea Camellia sinensis (CS) water extract had potent antitumor and antimetastatic effects on 4T1 breast cancer. The metronomic regimen $(0.0125 \mathrm{mg} / \mathrm{kg}$ twice a week for 4 weeks) of zoledronate (ZOL) was found to be effective in decreasing tumor burden and metastasis as compared with conventional regimen. The aim of the present study was to investigate the antitumor, antimetastatic and antiosteolytic effects of the combined use of CS water extract and metronomic ZOL against $4 \mathrm{~T} 1$ breast carcinoma in vitro and in vivo. The results demonstrated that the combination of CS+ZOL exerted a more potent effect on lung and liver by decreasing tumor burden and metastasis, when compared to CS or metronomic ZOL as monotherapies. The combination of $\mathrm{CS}+\mathrm{ZOL}$ demonstrated optimal bone protection against breast cancer-induced osteolysis for the three groups of CS, $\mathrm{ZOL}$ and $\mathrm{CS}+\mathrm{ZOL}$. The in vitro results further demonstrated that ZOL enhanced CS-induced apoptosis in 4T1 cells as assessed by the Annexin V-FITC/PI staining and caspase-3 activity assays. In addition, the combined use of $\mathrm{CS}+\mathrm{ZOL}$ significantly inhibited 4T1 cell migration. Mechanistic studies showed that the enzyme levels of matrix metalloproteinases (MMP)-2 and MMP-9 were suppressed significantly by $\mathrm{CS}+\mathrm{ZOL}$. In conclusion, to the best of our knowledge, this is the first study to investigate the novel combined application of herbal extract CS and chemotherapy ZOL in $4 \mathrm{~T} 1$ breast cancer.
\end{abstract}

Correspondence to: Professor Clara Bik-San Lau, E305, Science Centre East Block, Institute of Chinese Medicine, The Chinese University of Hong Kong, Shatin, New Territories, Hong Kong, SAR, P.R. China

E-mail: claralau@cuhk.edu.hk

Key words: Camellia sinensis, zoledronate, combination, antitumor, metastasis, osteolysis
The combination of CS plus metronomic ZOL demonstrated significant antitumor, antimetastatic and anti-osteolytic effects against breast cancer, and suggested potential clinical application for breast cancer patients.

\section{Introduction}

Green tea is a popular beverage consumed worldwide, which is obtained from the dried leaves of the plant Camellia sinensis (CS). Accumulating evidence has shown that green tea is beneficial to health. It was demonstrated that green tea polyphenols were able to act as direct antioxidants by scavenging reactive oxygen species or chelating transition metals (1). Clinical studies showed that green tea consumption was inversely associated with cardiovascular disease mortality (2). Epidemiological studies have shown that green tea extract induced thermogenesis and resulted in weight loss (3). A number of studies report the antitumor effects of CS and its polyphenolic components. The CS extract or tea polyphenol induced apoptosis and resulted in significant inhibition of tumor growth in various types of cancer including leukemia (4), prostate (5) and breast cancer (6). Recently, tea polyphenol EGCG from CS was used as adjuvant cancer therapy in combination with other chemotherapies (7). EGCG-induced chemosensitization of cancer cells through additive or synergistic effects with anticancer drugs has been identified in a number of preclinical, in vitro and in vivo studies (7). The effects of drugs such as 5-fluorouracil (8), doxorubicin (9) or tamoxifen (10) have been shown to be significantly increased when combined with EGCG in various types of cancer. In a previous study, we demonstrated that CS aqueous extract (mimic tea beverage) significantly inhibited 4T1 cell proliferation by inducing apoptosis and caspase-3, -8 and PARP activation, and increasing the expression of Bax-to-Bcl-2 ratio (11). CS also inhibited 4T1 cell migration and invasion dose dependently. In animal studies, the CS extract $(0.6 \mathrm{~g} / \mathrm{kg}$, orally-fed daily for 4 weeks) was effective in decreasing tumor weight, as well as lung and liver metastasis in mice bearing 4T1 tumors. Furthermore, micro-computed 
tomography ( $\mu$-CT) and in vitro osteoclast staining analysis demonstrated that CS extract was effective in bone protection against breast cancer-induced bone destruction (11). However, to the best of our knowledge, few studies have investigated the herb-drug interaction between CS extract and conventional anticancer agents.

Zoledronate (ZOL), the potent third-generation nitrogencontaining bisphosphonate, is effective in the prevention and treatment of bone destruction caused by the metastatic spread of primary cancer to the skeleton (12). ZOL exerted potential direct and indirect antitumor effects on in vitro and in vivo models. ZOL dose-dependently inhibited the proliferation of breast and prostate cancer, and osteosarcoma cells in vitro and induced apoptosis in these tumor cells $(13,14)$. Additionally, ZOL induced tumor cell adhesion, invasion and angiogenesis activities (15). Recent findings have shown that ZOL administered in a metronomic (repeated low-dose) manner appeared to be more effective than the conventional regimen in breast cancer patients as shown by the reduction of biomarkers $(16,17)$. Metronomic administration of ZOL also exhibited greater antitumor effects in a mouse model of breast cancer (18). Furthermore, Facchini et al demonstrated that the metronomic administration of $\mathrm{ZOL}$ and taxotere combination in castration-resistant prostate cancer patients showed promising antitumor activity (19). In a previous study, we demonstrated that metronomic ZOL $[0.0125 \mathrm{mg} /$ $\mathrm{kg}$ intraperitoneally (i.p.) injected twice a week for 4 weeks] was more effective than the conventional regimen $(0.1 \mathrm{mg} /$ $\mathrm{kg}$ i.p. injected once only) in reducing breast cancer tumor burden, and decreasing lung and liver metastasis in primary and metastatic breast cancer (20).

The present study aimed to investigate the antitumor, antimetastatic and anti-osteolytic effects of the combined use of CS aqueous extract and metronomic ZOL. The metronomic dose of ZOL used in the present study was $0.0125 \mathrm{mg} / \mathrm{kg}$, i.p. injected 8 times in 4 weeks, and the total amount was identical to that of the single conventional treatment of $0.1 \mathrm{mg} /$ $\mathrm{kg}$, although the metronomic method decreased the daily dose and increased the frequency. The 4T1 mouse mammary tumor model was employed to evaluate the antitumor, antimetastatic and anti-osteolytic effects of the combination of CS and metronomic ZOL, together with the individual treatment of CS or metronomic ZOL. Furthermore, the antiproliferative and apoptotic induction effects as well as the anti-migration and anti-invasion abilities of the combined use of CS and ZOL on mouse breast cancer 4T1 cells were assessed in vitro. Gelatin zymography analysis was employed to determine the underlying mechanism of the antimetastatic activities of CS and ZOL.

\section{Materials and methods}

Preparation of CS aqueous extract and high-performance liquid chromatography (HPLC) analysis. The dried leaves of green tea CS, whose origin is in the Hainan Province, China, were purchased from the herbal supplier of Hong Kong. A voucher specimen (no. 2011-3336) was kept in the museum of the Institute of Chinese Medicine, The Chinese University of Hong Kong. One kilogram of dried leaves of CS was soaked in one liter of boiled water for 15 min twice. Following the filtra- tion, the water extracts were combined and evaporated under reduced pressure at $60^{\circ} \mathrm{C}$ to dryness.

The chemical composition of the CS water extract was analyzed by HPLC (Agilent, Santa Clara, CA, USA) as previously described (21). Briefly, two-gradient elution system including mobile phase A [85\% orthophosphoric acid and water $(0.05: 99.95, \mathrm{v}: \mathrm{v})]$ and mobile phase B (acetonitrile) was employed. The gradient was running as: 0-4 min, $2 \% \mathrm{~B}$; 4-21 min, linear gradient from 2 to $9 \% \mathrm{~B} ; 21-32 \mathrm{~min}$, linear gradient from 9 to $23 \% \mathrm{~B} ; 32-45 \mathrm{~min}, 23 \% \mathrm{~B}$. The concentration of catechins in the CS extract was determined by HPLC.

Cells and reagents. Mouse mammary tumor cells (4T1) were obtained from the American Type Culture Collection (ATCC; Rockville, MD, USA), and cultured in RPMI-1640 medium containing $10 \%(\mathrm{v} / \mathrm{v})$ fetal bovine serum (FBS) and $1 \%(\mathrm{v} / \mathrm{v})$ penicillin-streptomycin (Life Technologies, Grand Island, $\mathrm{NY}, \mathrm{USA}$ ) at $37^{\circ} \mathrm{C}$ in $5 \% \mathrm{CO}_{2}$ humidified incubator.

ZOL was purchased from Novartis Pharma Stein, Switzerland. Transwell plates for Transwell migration assay were obtained from Corning Incorporated Life Sciences (Tewksbury, MA, USA). Alanine transaminase (ALT), aspartate transaminase (AST) and alkaline phosphatase (ALP) kits were purchased from Stanbio (Boerne, TX, USA). The 3-(4,5-dimethylthiazol-2-yl)-2,5-diphenyltetrazolium bromide (MTT) was obtained from Sigma (St. Louis, MO, USA). The caspase-3 activity assay kit was purchased from Life Technologies. The TUNEL assay kit (in situ cell death POD kit) was obtained from Roche, Mannheim, Germany. The Annexin V/PI double staining kit was purchased from BD Pharmingen (San Jose, CA, USA).

$4 T 1$ mouse mammary tumor model. The animal experiments were approved by the Animal Experimentation Ethics Committee of The Chinese University of Hong Kong (ref. no. 12/042/MIS). Female Balb/c mice (6-8 weeks old) were supplied by the Laboratory Animal Services Centre, The Chinese University of Hong Kong. The 4T1 cells $\left(4 \times 10^{5}\right)$ were resuspended in $100 \mu \mathrm{l}$ phosphate-buffered saline (PBS) and subcutaneously (s.c.) inoculated at the mammary fat pad of each mouse. Treatments were initiated 1 week after cancer cell implantation and lasted for 4 weeks. After 4T1 cell implantation, the tumor-bearing mice were randomly assigned into 4 groups $(n=10)$ : untreated control (orally fed with distilled water everyday); CS ( $0.6 \mathrm{~g} / \mathrm{kg}$ CS extract, orally fed everyday); ZOL (0.0125 mg/kg ZOL, i.p. injected twice a week); CS+ZOL $(0.6 \mathrm{~g} / \mathrm{kg} \mathrm{CS}$, orally fed everyday $+0.0125 \mathrm{mg} / \mathrm{kg}$ ZOL, i.p. injected twice a week). Naive mice without tumor and treatment were set as the normal standard. The body weight of each mouse was measured once a week during the treatment period. At day 28, the mice were sacrificed, and tumors, lungs and livers were removed for quantification of the tumor weight and burden. Tibias of mice from different groups were removed for $\mu$-CT analysis.

Hemato-biochemical markers were assessed by measuring the activities of liver-specific (ALT and AST) and bone-related (ALP) enzymes in the plasma using assay kits, after mice were treated with CS and/or ZOL. The average absorbance/minute was assessed, and then multiplied by a factor for results in units/liter (U/L). 
TUNEL assay. After mice were sacrificed, the tumors were removed and fixed in $10 \%$ formalin for 2 weeks at room temperature, embedded in paraffin, and then sectioned at a thickness of $5-\mu \mathrm{m}$. The level of cell apoptosis was determined with a Roche In Situ Cell Death POD kit according to the manufacturer's protocols. After de-waxation and rehydration, the tumor section was pretreated with proteinase $\mathrm{K}$ and $3 \%$ $\mathrm{H}_{2} \mathrm{O}_{2}$ solution. The stained tumor sections were photographed using an Olympus IX71 microscope (Japan) and analyzed using software ImageJ. Five fields of tumor sections (magnification, $\mathrm{x} 100$ ) were randomly selected, and the area of apoptotic cells in which nuclei stained as brown particles was calculated in each field. The apoptotic index (AI \%) was calculated as: Area of apoptotic cells/area of total tumor cells (22).

Histological analysis. Lungs and livers of tumor-bearing mice were fixed in $10 \%$ buffered formalin for 7 days at room temperature. The samples were paraffin embedded, sectioned longitudinally at $5 \mu \mathrm{m}$, and stained with hematoxylin and eosin (H\&E). The stained sections were examined and photographed using an Olympus IX71 microscope and SPOT advanced software (version 3.5.6). Five fields of lung or liver sections were randomly selected, and the area with $4 \mathrm{~T} 1$ tumors was calculated in each field. Tumor burden, defined as tumor area divided by the lung or liver area, was measured using ImageJ and expressed as an average percentage of the tumor area to lung or liver area.

$\mu$-CT analysis. Tibias removed from tumor-bearing mice were scanned with a high resolution microtomographic system, $\mu$-CT 40 (Scanco Medical AG, Switzerland). Each three-dimensional image data comprised an 500 micro-CT slide image $(8 \mu \mathrm{m} / \mathrm{slide})$ starting from the growth plate of tibial interface and moving down the tibia. Bone volume (BV) $\left(\mathrm{mm}^{3}\right)$ was generated from $\mu$-CT analysis and compared with the control tibia for each animal (18).

Cell viability assay. Cells $\left(1 \times 10^{4} /\right.$ well) in $100 \mu$ l culture medium were seeded in 96-well flat-bottomed plates (Corning) and incubated with CS $(0,0.025,0.05,0.1$ and $0.2 \mathrm{mg} / \mathrm{ml})$ and ZOL $(0,10,20$ and $30 \mu \mathrm{M})$ for $48 \mathrm{~h}$. Following incubation, the cells were subjected to MTT assay (20). Results were expressed as percentage of cell viability with respect to the untreated control cells (as 100\%). Only the most effective dose of ZOL was selected in subsequent studies and combined with $\mathrm{CS}$ at various concentrations $(0,0.05$ and $0.1 \mathrm{mg} / \mathrm{ml})$.

Annexin V-FITC/PI double staining. The $4 \mathrm{~T} 1$ cells $\left(3 \times 10^{5}\right)$ in $1 \mathrm{ml}$ culture medium were seeded in 6-well plates and incubated at $37^{\circ} \mathrm{C}$ for $24 \mathrm{~h}$. The cells were then treated with the combined use of CS $(0,0.05$ and $0.1 \mathrm{mg} / \mathrm{ml})$ and ZOL $(20 \mu \mathrm{M})$ for $24 \mathrm{~h}$. After incubation, the $4 \mathrm{~T} 1$ cells were collected and washed with PBS. Then the cells were stained in binding buffer containing Annexin V-FITC and PI for $15 \mathrm{~min}$ in the dark at room temperature. Subsequently, fluorescent signaling in the cells was detected by flow cytometry (FACSCanto II; Becton-Dickinson). Cell debris, characterized by a low forward scatter/side scatter, was excluded from the analysis. Positioning of quadrants on Annexin V/PI plots was performed to distinguish living cells (FITC- $/ \mathrm{PI}^{-}$), early apoptotic cells ( $\left.\mathrm{FITC}^{+} / \mathrm{PI}^{-}\right)$and late apoptotic or necrotic cells $\left(\mathrm{FITC}^{+} / \mathrm{PI}^{+}\right)$. The separation of the quadrants was adjusted by gating $>95 \%$ cells of negative control (i.e., $0 \mathrm{mg} / \mathrm{ml}$ ) into the left lower quadrant.

Caspase- 3 activity assay. The $4 \mathrm{~T} 1$ cells $\left(3 \times 10^{5}\right)$ in $1 \mathrm{ml}$ culture medium were seeded in 6 -well plates and incubated at $37^{\circ} \mathrm{C}$ for $24 \mathrm{~h}$. The cells were treated with the combination of CS $(0,0.05$ and $0.1 \mathrm{mg} / \mathrm{ml})$ and ZOL $(20 \mu \mathrm{M})$ for $24 \mathrm{~h}$, and subsequently collected and lysed in lysis buffer to determine the caspase- 3 activity, using the caspase-3 activity assay kit (Invitrogen) according to the manufacturer's instructions. The plate was then read at $405 \mathrm{~nm}$ in a microplate reader ( $\mu$ Quant; BioTek, Winooski, VT, USA). An increase of caspase-3 activity was determined by direct comparison to the level of the untreated control.

Scratch wound-healing assay. The 4T1 cells (1x105/well) in $1 \mathrm{ml}$ culture medium were seeded in 24-well plates and incubated at $37^{\circ} \mathrm{C}$ for $24 \mathrm{~h}$. After being starved in medium without FBS for $24 \mathrm{~h}$, the cells were scraped using $200 \mu \mathrm{l}$ pipette tips and the scratch was shaped like a cross. The medium was then replaced with fresh medium with CS $(0,0.05$ and $0.1 \mathrm{mg} / \mathrm{ml})$ and ZOL $(20 \mu \mathrm{M})$. The cells were incubated for $9 \mathrm{~h}$, and each well was photographed under a microscope (Nikon Eclipse TS100). The percentages of open wound area were measured and calculated using the TScratch software (23). Motility was determined by the decrease in the open wound area.

Transwell migration assay. The $4 \mathrm{~T} 1$ cells $\left(5 \times 10^{4}\right.$ in $\left.100 \mu \mathrm{l}\right)$ were added into each Transwell filter chamber with $1 \% \mathrm{v} / \mathrm{v}$ FBS. At the same time, $100 \mu \mathrm{l}$ of medium containing CS (0, 0.05 and $0.1 \mathrm{mg} / \mathrm{ml})$ and ZOL $(20 \mu \mathrm{M})$ (with $1 \% \mathrm{v} / \mathrm{v}$ FBS) was added to the upper Transwell chamber. Then, $500 \mu$ l complete medium (with $10 \% \mathrm{v} / \mathrm{v}$ FBS), served as chemoattractant medium, was added into the lower chamber. The cells were allowed to migrate through the Boyden chamber membrane to the lower chamber for $6 \mathrm{~h}$ at $37^{\circ} \mathrm{C}$, under $5 \% \mathrm{CO}_{2}$ conditions. After incubation, the cells were fixed with methanol, stained with hematoxylin and images were captured under a microscope (Nikon Eclipse TS100). The non-migrated cells on the top surface of the filter membrane were scraped with cotton swab. Stained filters were then photographed under microscope (Nikon Eclipse TS100). The migrated cells were quantified by manual counting in a blinded manner (24). Changes in cell numbers were presented as a percentage of control values (as 100\%).

Gelatin zymography. Cells $\left(1 \times 10^{5} /\right.$ well) in $1 \mathrm{ml}$ culture medium were seeded in 24-well plates and incubated with various concentrations of $\mathrm{CS}(0,0.05$ and $0.1 \mathrm{mg} / \mathrm{ml})$ at $37^{\circ} \mathrm{C}$ for $24 \mathrm{~h}$. The supernatant was collected and stored at $-80^{\circ} \mathrm{C}$. Protein sample $(20 \mu \mathrm{g})$ from the supernatant was fractionated in $10 \%$ SDS-polyacrylamide gel with $0.1 \%$ gelatin substrate. Following electrophoresis, the gels were washed three times in $2.5 \%$ Triton X-100 in PBS for $30 \mathrm{~min}$ at room temperature. The gels were then incubated overnight at room temperature in developing buffer (50 mM Tris base, $200 \mathrm{mM} \mathrm{NaCl}, 0.005 \mathrm{mM}$ $\mathrm{ZnCl}_{2}, 5 \mathrm{mM} \mathrm{CaCl} \cdot 2 \mathrm{H}_{2} \mathrm{O}$ and $\left.0.02 \% \mathrm{NaN}_{3}, \mathrm{pH} 7.5\right)$ and 
A

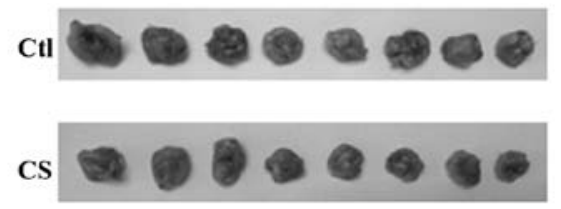

ZOL

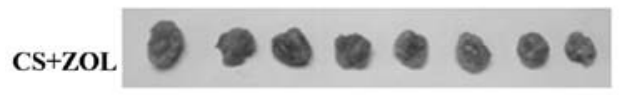

C

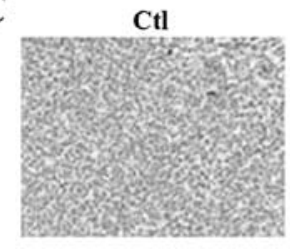

ZOL

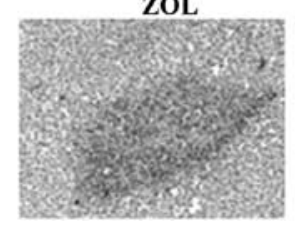

CS

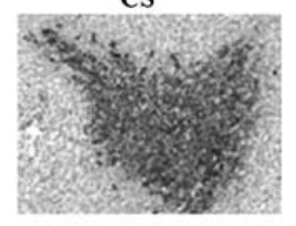

$\mathrm{CS}+\mathrm{ZOL}$

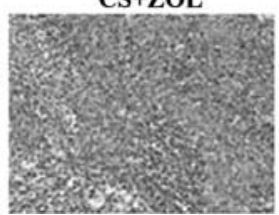

B

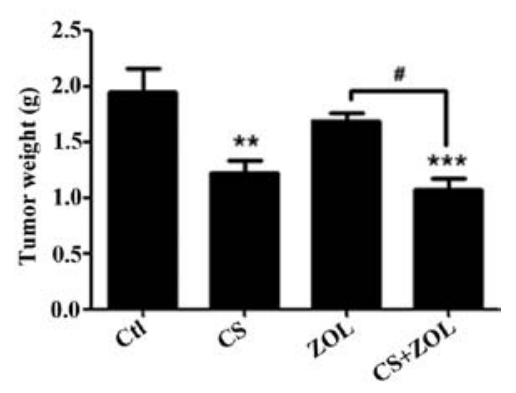

D

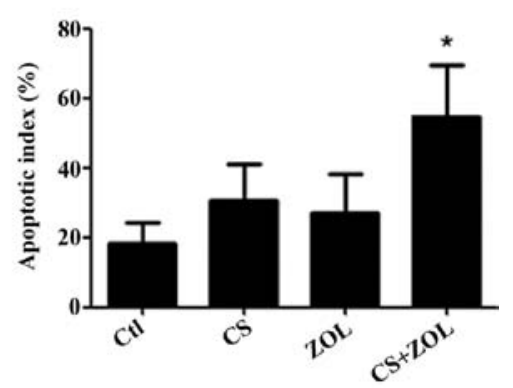

Figure 1. Effect of CS and/or ZOL on tumor weight in $4 \mathrm{~T} 1$ mouse mammary tumor model. (A) Representative tumor images from different groups. (B) The graph shows the tumor weight from different groups in 4T1 mouse mammary tumor model. (C) Treatments of CS, ZOL and CS+ZOL-induced tumor cell death as assessed by TUNEL assay. (D) Quantification of apoptotic cells in tumor sections according to the apoptotic index (\%), defined as the percentage of apoptotic cell area to the total tumor area. Data were presented as mean $+\mathrm{SEM}, \mathrm{n}=10 .{ }^{*} \mathrm{P}<0.05,{ }^{* *} \mathrm{p}<0.01$ and ${ }^{* * * *} \mathrm{p}<0.001$ as compared with control; ${ }^{\#} \mathrm{p}<0.05$. $\mathrm{Ctl}$, control group; CS, CS water extract treatment group in which mice were treated with $0.6 \mathrm{~g} / \mathrm{kg} \mathrm{CS}$ extract, orally fed everyday; ZOL, metronomic ZOL treatment group in which mice were treated with $0.0125 \mathrm{mg} / \mathrm{kg}$ ZOL, i.p. injected twice a week for 4 weeks; CS+ZOL, the combination treatment group in which mice were treated with CS plus ZOL, and the dose was identical to the individual treatment of CS or ZOL. CS, Camellia sinensis; ZOL, zoledronate.

then stained with $0.125 \%$ (w/v) Coomassie brilliant blue for 20-30 min and destained in destaining buffer (10\% acetic acid and 5\% ethanol in distilled water) for 1-2 days. Visualization of bands was performed on a Bio-Rad, XBS+ Imaging System (Bio-Rad, Hercules, CA, USA).

Statistical analysis. Data were presented as mean \pm SD (for in vitro studies) or SEM (for in vivo studies). Statistical analysis was performed using one-way ANOVA. $\mathrm{P}<0.05$ was considered to indicate a statistically significant result.

\section{Results}

HPLC analysis of polyphenols of CS aqueous extract. The chemical composition of tea polyphenols in CS extract was analyzed by HPLC. The CS water extract contained large amount of tea polyphenol of $25 \%$, with EGCG as the most abundant, followed by EGC, ECG and EC. Detailed information is provided in a previous study (11).

Effect of combination therapy on $4 T 1$ tumor growth and apoptotic induction. To investigate the activities of the combined use of CS plus metronomic ZOL on tumor growth and metastasis, a mammary fat pad model was employed, in which cells were injected into the mammary fat pad of female BALB/c mice. The results showed that no significant body weight loss was found in any of the treatment groups (data not shown). Tumors from different groups shown in Fig. 1A, reveal that 4T1 mammary tumors were decreased significantly in the CS and CS+ZOL groups by 36.2 and $45.1 \%$, respectively, as compared to the untreated control (Fig. 1B). The combination of CS+ZOL showed the lowest tumor weight among the three groups, and a significant difference was observed between the CS+ZOL and ZOL monotherapy groups (Fig. 1B). In addition, the apoptotic index (\%) in tumor, defined as the percentage of apoptotic cell area to the total tumor area, was assessed using TUNEL assay. As shown in Fig. 1C and D, treatment of CS, $\mathrm{ZOL}$ and $\mathrm{CS}+\mathrm{ZOL}$ resulted in an increase in tumor cell death in $4 \mathrm{~T} 1$ tumors. The combination of $\mathrm{CS}+\mathrm{ZOL}$ showed a higher apoptotic index against the individual treatment of $\mathrm{CS}$ or $\mathrm{ZOL}$ alone and significant difference was identified $(\mathrm{p}<0.05)$.

Effect of combination therapy on lung and liver metastasis. Lungs and livers from each mouse were removed for histological analysis and assessment of lung and liver metastasis. Fig. 2A and B shows the representative histological sections of lungs and livers from different groups. Large 4T1 tumors were found in the untreated control group (with arrows shown in lung and liver in the image), while the tumor area and nodules were decreased in all the treatment groups. Tumor burden in lung was found to be decreased by $76.4 \%$ (lung metastasis decreased from 8.9 to $2.1 \%$ ), $68.5 \%$ (decreased from 8.9 to $2.8 \%$ ) and $80.8 \%$ (decreased from 8.9 to $1.7 \%$ ) in CS-, ZOL- and (CS+ZOL)-treated groups respectively, 

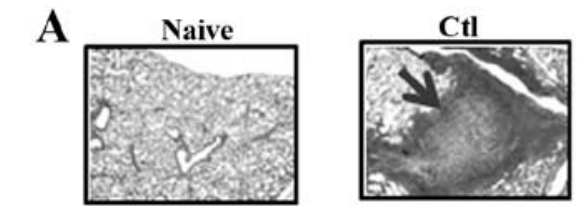

CS

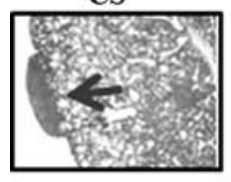

ZOL
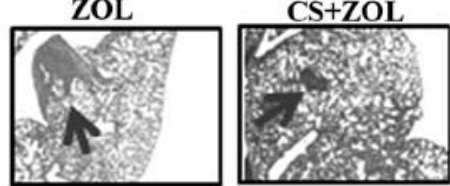

C

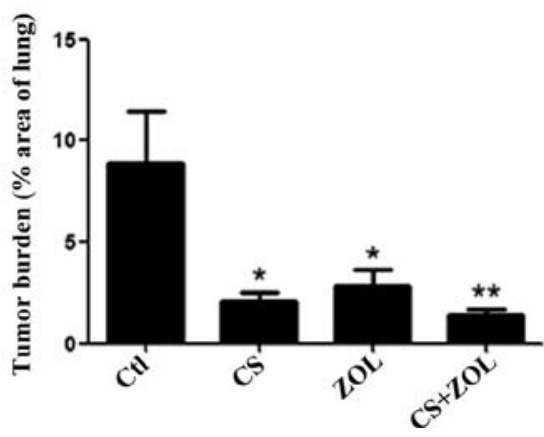

B
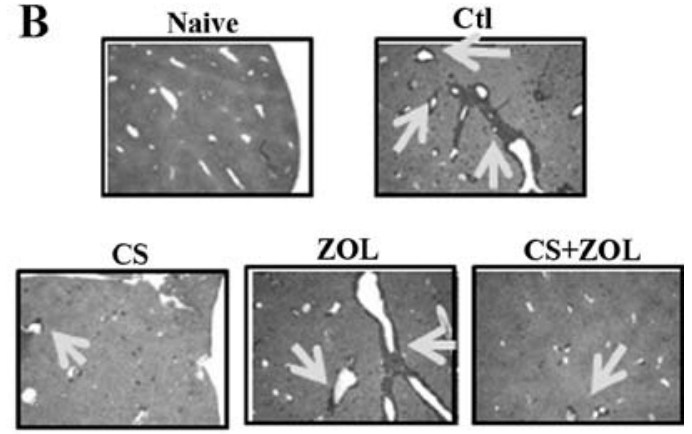

D

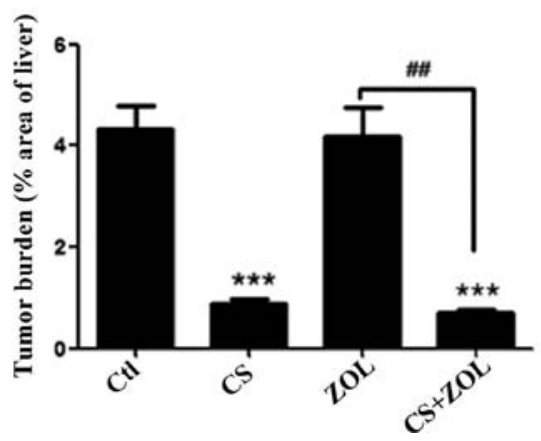

Figure 2. Effects of CS and/or ZOL on lung and liver metastasis in mouse orthotopic breast cancer. (A and B) Representative H\&E-stained sections of (A) mouse lungs and (B) livers from different groups with arrows showing the 4T1 tumors. Histological sections of the lungs and livers were photographed and used to measure tumor area and total lung or liver area. (C and D) The graphs show the tumor burden in (C) lungs and (D) livers according to the tumor area as a percentage of whole lung or liver area/group. Data shown are an average percentage of the tumor area to lung or liver area/group. Mean + SEM, $n=10$. ${ }^{*} \mathrm{P}<0.05,{ }^{* *} \mathrm{p}<0.01$ and ${ }^{* * *} \mathrm{p}<0.001$ as compared with the control; ${ }^{\# \#} \mathrm{p}<0.01$. Ctl, control group comprising tumor-bearing mice treated with distilled water. Naive, normal mice without tumor and treatment. CS, Camellia sinensis; ZOL, zoledronate; H\&E, hematoxylin and eosin.

against untreated control group (Fig. 2C). Of the three treatment groups, the combination of CS+ZOL showed the highest inhibition of lung metastasis. Similar results were found in liver metastasis. Liver metastasis was decreased significantly following CS and CS+ZOL treatments, while no obvious effect was evident in the ZOL-treated group. A significant difference was observed between $\mathrm{ZOL}$ and the combination of $\mathrm{CS}+\mathrm{ZOL}$ $(\mathrm{p}<0.01)$ (Fig. 2D).

Effect of combination therapy on breast cancer-induced osteolysis. At the late stage of cancer propagation, breast cancer cells metastasize to bone and induce severe bone destruction (25). To assess the efficacy of CS and/or ZOL against breast cancer-induced bone destruction, $\mu$-CT analysis was employed. The 3D $\mu$-CT images of representative tibia from the control group demonstrated significant bone destruction when compared to the corresponding tibia from the non-tumorbearing naive group (Fig. 3A). Animals treated with CS, ZOL and $\mathrm{CS}+\mathrm{ZOL}$ showed significant preservation of the bone structure. As shown in Fig. 3B, the bone volume (BV) in the control group was $2.87 \mathrm{~mm}^{3}$, lost nearly $18 \%$ of $\mathrm{BV}$ when compared to the BV of the naive group, indicating severe bone destruction in the control group. By contrast, treatments with $\mathrm{CS}, \mathrm{ZOL}$ and $\mathrm{CS}+\mathrm{ZOL}$ resulted in a marked increase of $\mathrm{BV}$ in tumor-bearing mice of $15.1,43.2$ and $45.1 \%$, respectively. No significant difference was shown between ZOL and CS+ZOL, while a significant difference was identified between CS and the combination of the CS+ZOL treatment groups. The marked anti-osteolytic effect of CS+ZOL may be due to the effect of ZOL, which is a clinical drug that is commonly used in the treatment of bone disorders by inhibiting osteoclastic bone resorption.

The bone-related enzyme ALP in plasma of mice was assessed after treatments with CS and/or ZOL. As shown in Fig. 4A, no significant difference was shown in the treatment groups and the untreated control. However, the ALP level in the non-tumor-bearing naive group was higher than that in the tumor-bearing mice groups, indicating the damage of the 4T1 tumor to the bone.

Effect of the combination therapy on hemato-biochemical markers. Hemato-biochemical markers in mice plasma were tested following treatment with CS and/or ZOL by measuring the plasma activities of liver-specific (ALT and AST) enzymes. As shown in Fig. 4B and $\mathrm{C}$, no significant difference was shown in CS-, ZOL- and CS+ZOL-treated groups on plasma activities of liver-specific enzymes, indicating no obvious damage of the treatments to the liver.

Effect of the combined use of CS and ZOL on the viability of $4 T 1$ cells. An MTT assay was performed to assess the effect of ZOL as a single agent and in combination with CS at different concentrations on the viability of 4T1 breast cancer cells, and the most effective dose of the combination treatment was selected for subsequent studies. As shown in Fig. 5, the growth of $4 \mathrm{~T} 1$ cells was suppressed by 10,20 and $30 \mu \mathrm{M}$ ZOL in the presence of various concentrations of CS in a dose-dependent manner. The combination of ZOL and CS demonstrated 
A
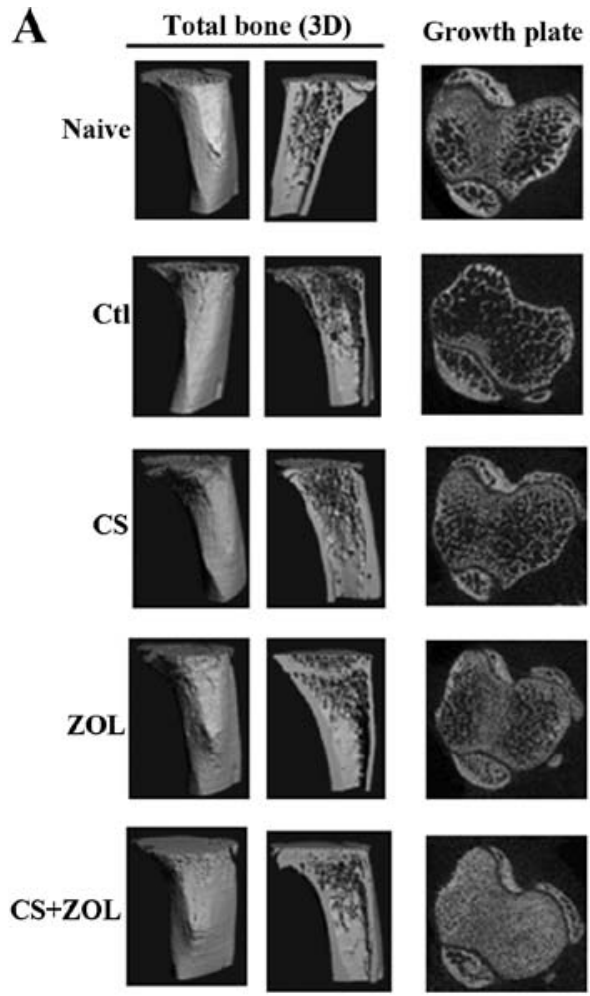

B

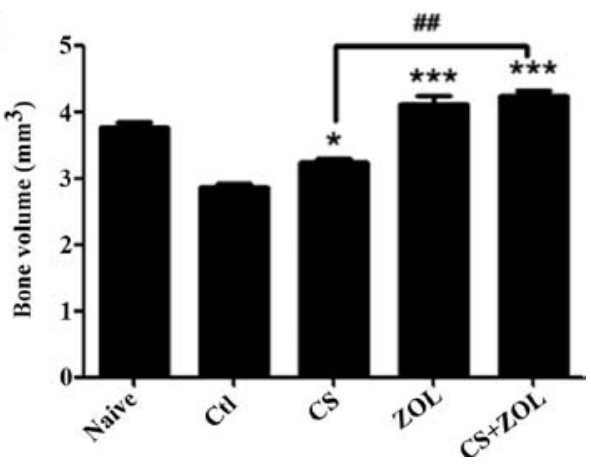

Figure 3. Qualitative and quantitative assessment of bone structure in mouse tibias after CS and/or ZOL treatments. (A) Representative $\mu$-CT 3D images, section-cut and growth plate of mouse tibias obtained from different groups. (B) The graph shows the bone volume of tibias from different groups. Data were expressed as mean + SEM, $n=10$. ${ }^{*} \mathrm{p}<0.05$ and ${ }^{* * *} \mathrm{p}<0.001$ as compared with control; ${ }^{\#} \mathrm{p}<0.01$. Ctl, control group. Naive, normal mice without tumor and treatment. CS, Camellia sinensis; ZOL, zoledronate.

additive cytotoxic effects, particularly at the doses of $20 \mu \mathrm{M}$ ZOL plus $0.1 \mathrm{mg} / \mathrm{ml}$ of CS, which produced an inhibition of $58.5 \%$ cell viability, while ZOL and CS added alone caused inhibition rates of 22.1 and $33.3 \%$, respectively. Since the combination of ZOL $(20 \mu \mathrm{M})$ and $\mathrm{CS}(0.1 \mathrm{mg} / \mathrm{ml})$ has the best additive inhibition activity on cell viability, this combinatorial dose was selected for subsequent experiments.

Effect of the combined use of CS and ZOL on apoptotic induction. Treatment of $4 \mathrm{~T} 1$ cells with CS extract resulted in increasing number of apoptotic cells (early and late stages of apoptotic cells) when compared to the untreated control (Fig. 6A). The percentage of apoptotic cells following treatment with 0.1 or $0.2 \mathrm{mg} / \mathrm{ml}$ of CS extract for $24 \mathrm{~h}$ were found to be 11 or $34.1 \%$, respectively. ZOL $(20 \mu \mathrm{M})$ alone resulted in $7.6 \%$ of apoptotic cells. However, greater level of apoptosis was
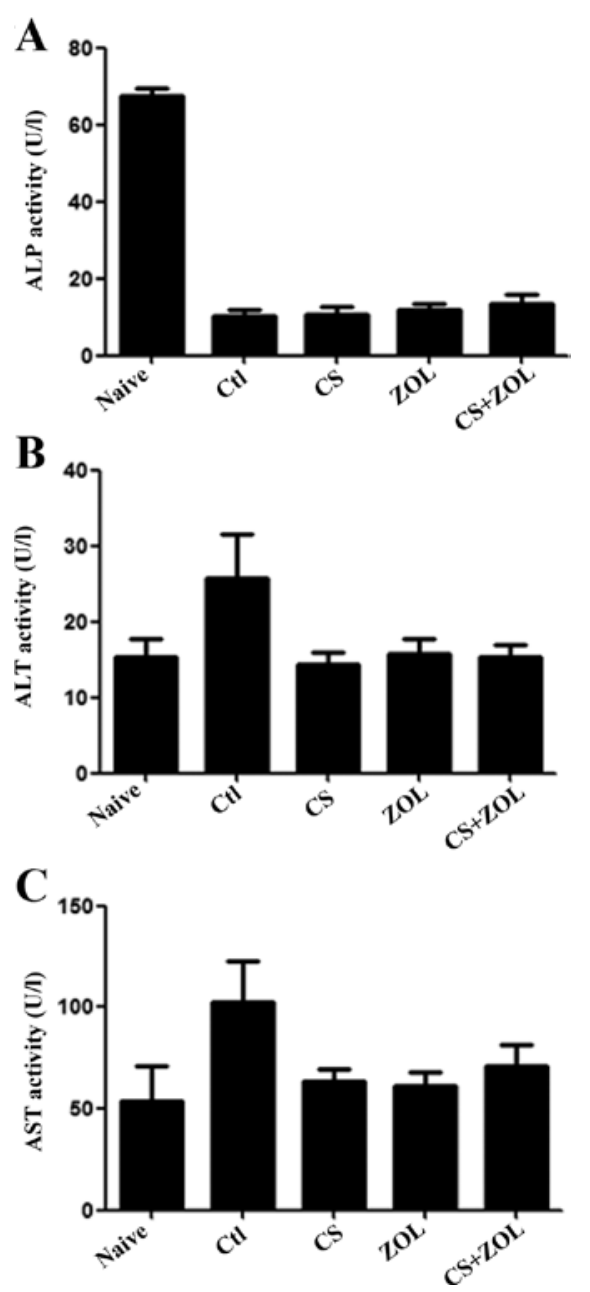

Figure 4. (A-C) Evaluation of the hemato-biochemical markers (ALP, ALT and AST) of mouse plasma following treatment with CS and/or ZOL. After mice were sacrificed, plasma activities of liver-specific (AST and ALT) and bone-related (ALP) enzymes were assessed. Data are presented as mean + SEM, $n=10$. ALP, alkaline phosphatase; ALT, alanine transaminase; AST, aspartate transaminase; CS, Camellia sinensis; ZOL, zoledronate.

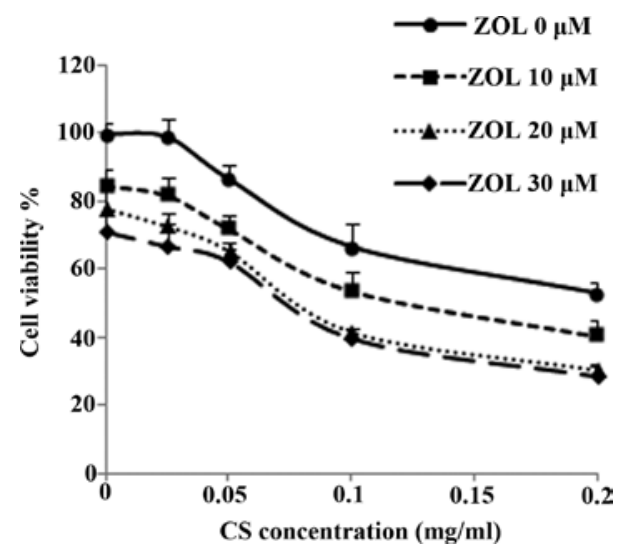

Figure 5. Effects of ZOL in combination with CS at various concentrations on $4 \mathrm{~T} 1$ cells viability. Cells were incubated with ZOL $(0,10,20$ and $30 \mu \mathrm{M})$ in the presence of various concentrations of CS after $48 \mathrm{~h}$ treatment. Data are presented as mean $+\mathrm{SD}(\mathrm{n}=3)$. ZOL, zoledronate; $\mathrm{CS}$, Camellia sinensis.

observed after CS $(0.1$ or $0.2 \mathrm{mg} / \mathrm{ml})$ was combined with ZOL $(20 \mu \mathrm{M})$, and the percentage of apoptotic cells was found to be 43 and $66 \%$, respectively, with significant differences being 
A

CS
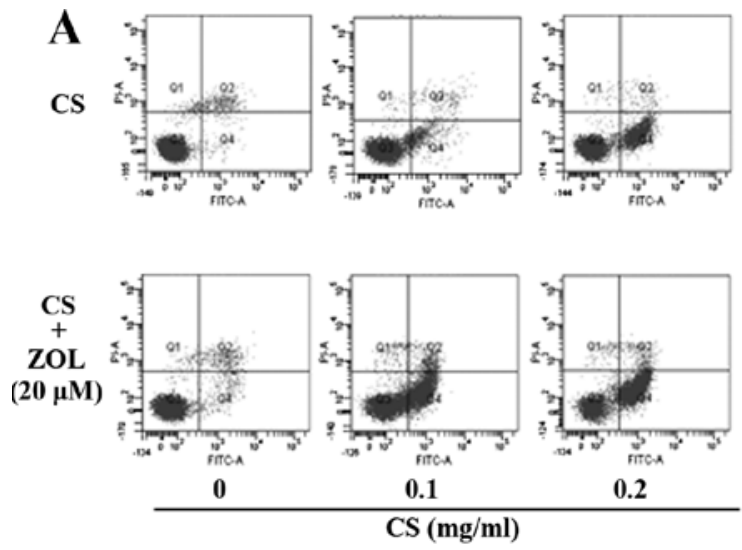

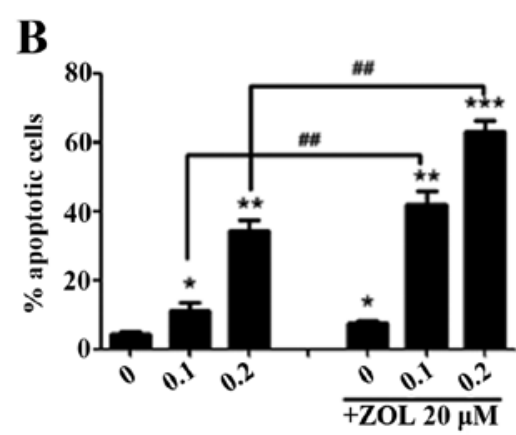

CS concentration $(\mathrm{mg} / \mathrm{ml})$

C

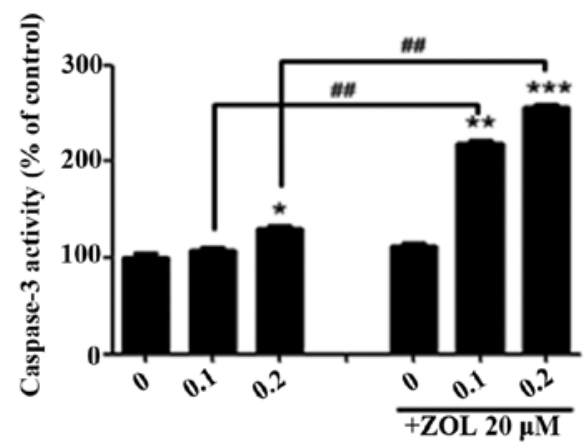

Figure 6. Induction of apoptosis on $4 \mathrm{~T} 1$ cells following treatment with CS or CS and ZOL. (A) CS and ZOL induced apoptosis in 4T1 cells as assessed by Annexin V-FITC/PI staining. Cells stained with Annexin V-FITC and PI were detected by flow cytometry. The lower right quadrant (Annexin $\mathrm{V}^{+} / \mathrm{PI}^{-}$) shows early apoptosis, while the upper right quadrant $\left(\right.$ Annexin $\left.\mathrm{V}^{+} / \mathrm{PI}^{+}\right)$ shows late apoptosis. (B) Quantitative analysis of the percentage of apoptotic cells of CS after $24 \mathrm{~h}$ incubation. Data are presented as mean $+\mathrm{SD}(\mathrm{n}=3)$. (C) Caspase-3 activity test of 4T1 cells after incubation with CS and ZOL. Data were presented as mean $+\mathrm{SD}(\mathrm{n}=3) .{ }^{*} \mathrm{P}<0.05,{ }^{* *} \mathrm{p}<0.01$ and ${ }^{* * *} \mathrm{p}<0.001$ as compared with the control; ${ }^{\#} \mathrm{p}<0.05$ and ${ }^{\# \#} \mathrm{p}<0.01$. CS, Camellia sinensis;

CS concentration $(\mathrm{mg} / \mathrm{ml})$ ZOL, zoledronate.

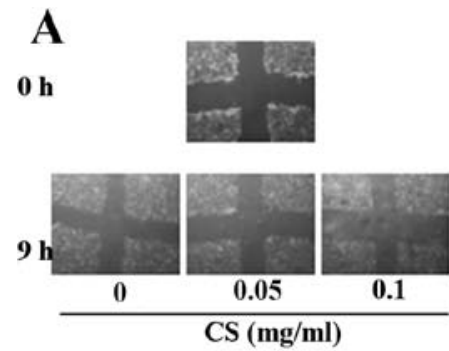

C

CS
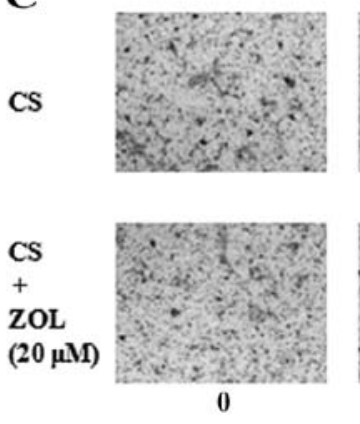
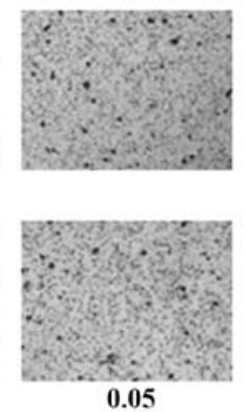

0.05
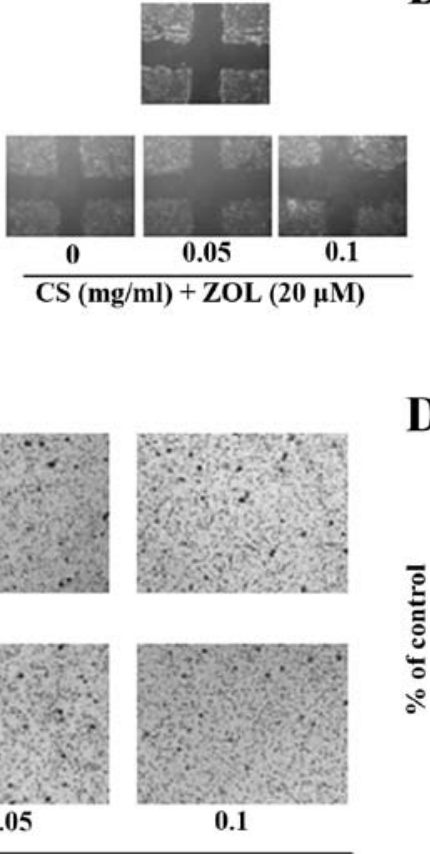

$\mathrm{CS}(\mathrm{mg} / \mathrm{ml})$
D

B

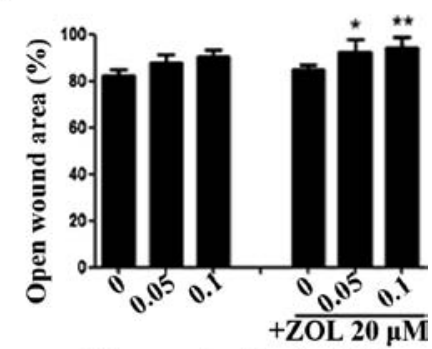

CS concentration $(\mathrm{mg} / \mathrm{ml})$

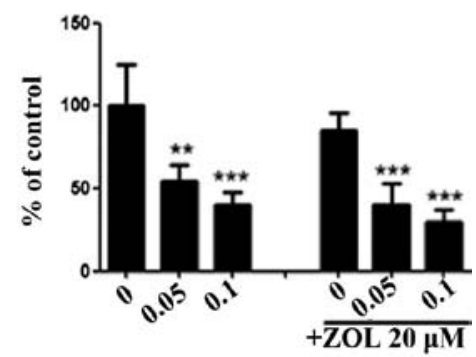

CS concentration $(\mathrm{mg} / \mathrm{ml})$

Figure 7. Effect of CS or CS+ZOL on the $4 \mathrm{~T} 1$ cell migration and invasion. (A) Representative images of the wounded cell monolayers of $4 \mathrm{~T} 1$ cells after incubation with various concentrations of CS and a fixed amount of ZOL $(20 \mu \mathrm{M})$. (B) Quantitative analysis of the migration activity of cells after $9 \mathrm{~h}$ treatment of CS or CS+ZOL. (C) Representative images of the stained 4T1 cells. (D) Quantitative analysis of the invasion activity of cells following treatment with CS or CS+ZOL. Data are presented as mean $+\mathrm{SD}(\mathrm{n}=3) .{ }^{*} \mathrm{P}<0.05,{ }^{* *} \mathrm{p}<0.01$ and ${ }^{* * *} \mathrm{p}<0.001$, as compared with the corresponding untreated control. CS, Camellia sinensis; ZOL, zoledronate.

observed for the individual treatment of $\mathrm{CS}(\mathrm{p}<0.05)$ (Fig. 6B). Furthermore, CS-induced 4T1 cell apoptosis was concomitant with a dose-associated increase in caspase-3 activity, and ZOL synergistically enhanced the CS-induced apoptosis in 4T1 cells, while ZOL $(20 \mu \mathrm{M})$ alone resulted in no obvious increase of caspase-3 activity (Fig. 6C). 
A
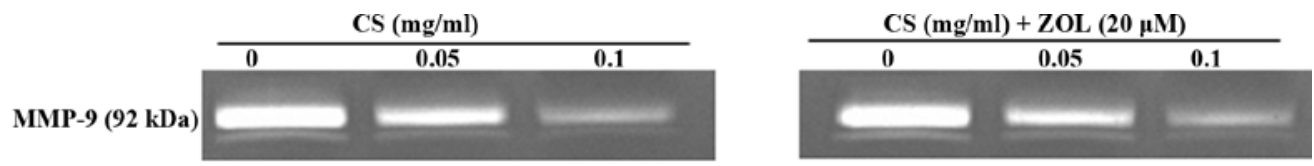

MMP-2 (72 kDa)
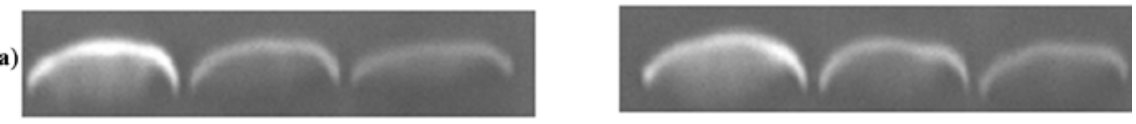

B

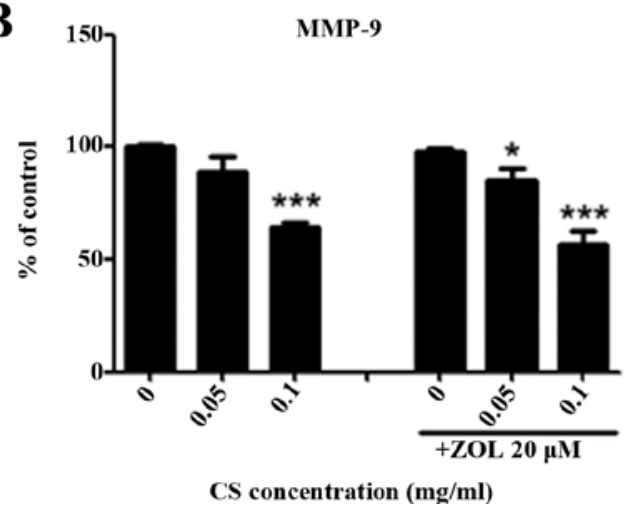

C

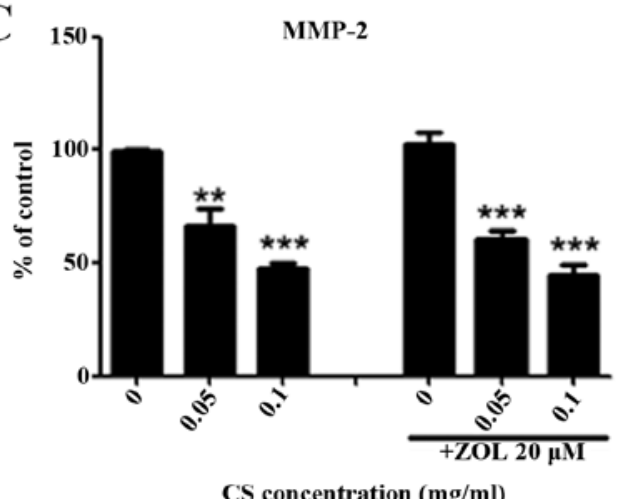

Figure 8. Effect of CS and/or ZOL on MMP-2 and MMP-9 activities. Representative zymograms are shown on 4T1 cells after treated with CS and/or ZOL for $24 \mathrm{~h}(\mathrm{n}=3) .{ }^{*} \mathrm{P}<0.05,{ }^{* *} \mathrm{p}<0.01$ and ${ }^{* * *} \mathrm{p}<0.001$, as compared with control. CS, Camellia sinensis; ZOL, zoledronate.

Effect of combined use of CS and ZOL on 4T1 cell migration and invasion. Treatment with CS alone had some effect on the inhibition of cell migration of 4T1 cells. However, no significant difference was observed in the CS-treated group. ZOL $(20 \mu \mathrm{M})$ alone induced no significant increase in the open wound area. However, a greater level of increase in the open wound area on 4T1 cells was observed when the cells were treated with $\mathrm{CS}+\mathrm{ZOL}$, and significant differences were observed $(\mathrm{p}<0.05)$ (Fig. 7A and B), indicating the combination of CS+ZOL inhibited 4T1 cell migration and thus increased the open wound area. Thus ZOL strengthened the inhibitory effect of CS against 4T1 cell migration.

In order to determine the efficacy of CS and ZOL against cancer cell invasion in vitro, the Transwell migration assay was performed. Treatment of CS at 0.05 and $0.1 \mathrm{mg} / \mathrm{ml}$ resulted in significant inhibition of 4T1 cell invasion. ZOL $(20 \mu \mathrm{M})$ led to a non-significant decrease (16\%) of the 4T1-invasive ability, and the addition of ZOL to CS did not improve the anti-invasive properties of CS. A greater level of inhibition on cell invasion was observed after CS was combined with ZOL, the cell invasion was inhibited by 61 and $72 \%$ at 0.05 and $0.1 \mathrm{mg} / \mathrm{ml}$, respectively, of CS+ZOL $(20 \mu \mathrm{M})$. However, no significant difference was identified between the CS+ZOL and the individual treatments of CS or ZOL alone.

Effect of the combined use of CS and ZOL on MMP-2 and MMP-9 activities. Gelatin zymography was carried out to assess the effect of CS and/or ZOL on the activity of matrix metalloproteinases (MMP)-2 and -9 , which played an important role in extracellular matrix and basement membrane degradation (26). As shown in Fig. 8A, MMP-2 and MMP-9 in the 4T1 cell culture supernatant were detected in the gel at molecular weight of 72 and $92 \mathrm{kDa}$, respectively. The MMP-2 and MMP-9 digested the gelatin substrate significantly, and clear bands were presented in control. Treatment with CS or $\mathrm{CS}+\mathrm{ZOL}$ resulted in the reduction of the bands, indicating the suppression of the enzyme activities of MMP-2 or MMP-9. The enzyme activity of MMP-2 and MMP-9 was significantly suppressed by CS, and greater levels of suppression on MMP-9 and MMP-2 were observed in the combination of CS and ZOL. However, no significant difference was identified between the combination of CS+ZOL and the individual treatment of CS alone (Fig. 8B and C).

\section{Discussion}

Combination therapy, in which one or more medication or therapies are used simultaneously, is an effective cure for cancer treatment (27). An optimal combination therapy of antitumor agents results in synergistic or additive therapeutic efficacy, including increased activity, decreased side-effects and minimal or delayed drug resistance, whereas some unsatisfactory combinations may produce antagonistic efficacy (28). Patients with cancer frequently use herbal medicine along with conventional medical treatments to enhance the efficacy of drugs, remove the unwanted side-effects and obtain additional protection. Over half (53.9\%) of cancer patients in Hong Kong took Chinese herbal medicines along with chemotherapeutic agents (29). A clinical study from mainland China showed that treatment with integrated traditional Chinese and Western medicines for advanced gastric cardia carcinoma in 26 cases resulted in 57\% remission in patients when compared to untreated individual (30). The Chinese herbal medicine Yun Zhi (Coriolus versicolor) preparation used in combination with chemotherapy in patients with breast, gastric or colorectal cancer, resulted in a significant survival advantage when compared with the conventional anticancer chemotherapy alone (31). Green tea polyphenol EGCG acted synergistically 
in combination with clinical anticancer drugs cisplatin and designed trans-palladiums in ovarian cancer cells (32). There is an increasing trend in cancer treatment and research to use combination therapy for advanced types of cancer (31-33). In the present study, we aimed to determine whether a synergistic or additive effect would be identified in the combination treatment of the Chinese herbal extract of Camellia sinensis (CS) and metronomic regimen of zoledronate (ZOL) against tumor growth, metastasis and bone destruction in a 4T1 mouse mammary tumor model. The metronomic dose of ZOL used in the present study was $0.0125 \mathrm{mg} / \mathrm{kg}$, i.p. injected 8 times in 4 weeks, and the total amount was identical to that of the single conventional treatment of $0.1 \mathrm{mg} / \mathrm{kg}$. However, the metronomic manner decreased the daily dose and increased the frequency (20).

In the 4T1 mouse mammary tumor model, the 4T1 mouse mammary carcinoma cells were injected orthotopically into the mammary fat pad of the female BALB/c mice directly. Due to the high aggressivity and metastatic characteristics of 4T1 cells, it is easy to establish metastasis to lung and liver, as well as in bone (34). Therefore, the antitumor and antimetastatic effects were assessed in this model. After treatments with CS or CS+ZOL, tumor weights in the orthotopic site were decreased significantly, and no significant body weight loss was identified. The combined use of CS and metronomic ZOL showed improved antitumor effect against the individual treatments of CS or metronomic ZOL. In order to determine whether the apoptotic process occurred in mammary tumors, TUNEL assay was employed. Treatment of CS, ZOL and CS+ZOL resulted in cell death in 4T1 tumors, and the combination of CS and metronomic ZOL showed the most potent apoptotic induction among the three groups. The findings suggest that CS and metronomic ZOL exerted better effects than the individual treatments. Apoptosis plays a crucial role in cancer propagation, which was considered as a protective mechanism against the development and progression of cancer (35).

The 4T1 cells are documented to be highly invasive and to develop tumor metastasis to the lung, liver and bone after primary tumor was established for 2-3 weeks in BALB/c mice (34). Following treatment with $\mathrm{CS}, \mathrm{ZOL}$ and $\mathrm{CS}+\mathrm{ZOL}$, tumor burden in lung was decreased significantly against the untreated control group. Consistent results were also identified in liver metastasis, except that metronomic ZOL had no obvious effect on inhibiting liver metastasis. Previous findings showed that tea polyphenols from CS were effective in decreasing metastasis of tumor cells to lungs in mice bearing 4T1 tumors (36). The present study has demonstrated that the combination of CS and metronomic ZOL had improved results in decreasing lung and liver metastasis in contrast to the individual treatment only, suggesting that CS and metronomic ZOL cooperated in inhibiting tumor metastasis.

Apart from lung and liver metastasis, bone destruction was also assessed using $\mu$-CT analysis. It was determined that treatment with $\mathrm{CS}, \mathrm{ZOL}$ and $\mathrm{CS}+\mathrm{ZOL}$ resulted in a marked increase of $\mathrm{BV}$ in mice of $15.1,43.2$ and $45.1 \%$, respectively, and the combined use had an optimal result among the 3 groups. It has been demonstrated that CS ingredients such as tea polyphenols EGCG and EGC showed significant effects in inhibiting formation of osteoclasts $(37,38)$. A recent animal study further confirmed the finding that EGCG decreased ovariectomy-induced bone loss in mice via inhibition of osteoclasts (39). In addition, ZOL is a clinical drug that is commonly used in the treatment of bone disorders by inhibiting osteoclastic bone resorption (40). ZOL inhibits osteoclastic bone resorption by preventing prenylation of GTPases and ultimately induces cell death in osteoclasts (41). Our previous study demonstrated that metronomic ZOL also had significant anti-osteolytic effect (20). In the present study, the combination of CS and metronomic ZOL was firstly demonstrated to have great potential in anti-osteolytic effects.

In addition, hemato-biochemical marker (ALP, ALT and AST) tests were performed following treatment with CS and/or metronomic ZOL. No significant difference was identified on the enzymes level of ALT and AST in the treatment groups, suggesting that CS and metronomic ZOL had no obvious damage to the liver. The ALP activities in normal naive mice were higher than those of the control, which may be due to the growth of th e4T1 tumor. It was demonstrated that 4T1 cells are highly invasive and have metastatic characteristics exhibiting primary tumor metastases to lung, liver and bone as early as 2 weeks after inoculation (34). Our results have shown significant bone destruction induced by 4T1 cancer, particularly in the control group. Any condition of bone growth may cause the elevation of ALP levels (42). The high level of ALP in normal naive mice may be due to bone growth. While in the 4T1 tumor-bearing mice, the bone was destroyed by the metastasized breast cancer cells and the bone growth was retarded, the ALP level was decreased in tumorbearing groups as compared to the naive group.

Furthermore, the in vitro apoptosis induction of the combination of $\mathrm{CS}$ and ZOL was assessed. The combination of ZOL $(20 \mu \mathrm{M})$ and CS $(0.1 \mathrm{mg} / \mathrm{ml})$ in $4 \mathrm{~T} 1$ cells have the best additive inhibition on cell viability, and the doses of the combination were selected in the subsequent studies. The results from Annexin V-FITC/PI double staining and caspase- 3 activity assays demonstrated that $4 \mathrm{~T} 1$ cells treated with the CS water extract resulted in an increased number of apoptotic cells in a dose-dependent manner. A greater level of apoptosis was observed after CS was combined with ZOL, and significant differences were shown between individual CS treatment and the combination of CS and ZOL (Fig. 6). The results suggest that ZOL synergistically enhanced CS-induced apoptosis in $4 \mathrm{~T} 1$ cells. The in vitro findings demonstrated by Annexin V-FITC/PI staining and caspase-3 activity assays were completely in concordance with the TUNEL results from tumor sections showing that ZOL synergistically enhanced CS-induced apoptosis in 4T1 cells.

The anti-migration and anti-invasion abilities of CS and/or ZOL were also assessed. The combination of CS plus ZOL inhibited 4T1 cell migration, and a significant difference was observed, indicating that ZOL strengthened the inhibitory effect of CS on cell migration against 4T1 cells. Previous studies showed that ZOL significantly prevented cell migration in MDA-MB-231 breast cancer cells (43), and CS water extract was effective in inhibiting the proliferation and migration of human SW620 colon cancer cells (44). Our results show that the combination of CS and ZOL had a greater level of inhibition on 4T1 cell migration against the individual treatment of $\mathrm{CS}$ or ZOL. In the invasion assay, no additive or synergistic effect was shown in the combined use of CS and ZOL on 4T1 
cell invasion. The reason for this finding may be due to the high dose of CS herbal extract used in this assay, and that treatment of CS alone already resulted in significant inhibition of cell invasion. In addition, results of the mechanistic study showed that the enzyme activity of MMP-2 and MMP-9 was significantly suppressed by CS plus ZOL, indicating the potent antimetastatic effect of the combined use of CS and ZOL. The in vitro findings showed that the combined use of $\mathrm{CS}+\mathrm{ZOL}$ inhibited 4T1 cell migration and invasion significantly, which may partly explain the activity of $\mathrm{CS}+\mathrm{ZOL}$ in the inhibition of tumor metastasis to lung and liver in vivo. As demonstrated by Oppenheimer, cell migration is the first step of the invasive process and plays an important role in tumor metastasis (45).

Although the underlying mechanism of the antitumor and antimetastatic effects of the combined use of CS+ZOL was not well investigated in the present study, studies have demonstrated the apoptotic induction and antimetastatic effects of CS or ZOL. Baliga et al found that green tea CS extract inhibited 4T1 cell proliferation and induced apoptosis in this cell line by activation of caspase-3 and PARP (36). In addition, our results revealed that $\mathrm{CS}$ suppressed the enzyme levels of MMP-2 and MMP-9 significantly in 4T1 cells, suggesting that CS had potent antimetastatic effects. On the other hand, previous studies have demonstrated that ZOL induced apoptosis in 4T1 cells via the activation of caspase-3, and inhibited visceral metastasis in a 4T1 mouse breast cancer model (46). ZOL also prevented cell migration and invasion in MDA-MB-231 breast cancer cells (43).

In summary, to the best of our knowledge, our results present the first evidence on the combination of Chinese herbal extract CS and conventional drug ZOL against tumor growth, metastasis and bone destruction in a 4T1 mouse tumor model. The combination of CS and metronomic ZOL cooperated in decreasing tumor burden and metastasis, and significantly inhibited the breast cancer-induced bone destruction in a 4T1 mouse model. Additionally, the combined use of CS and ZOL inhibited cell migration and invasion, and induced apoptosis in 4T1 cells. The novel application of herbal extract CS plus metronomic ZOL promoted the antitumor, antimetastatic and anti-osteolytic effects of ZOL against metastatic breast cancer. The metronomic dose means more frequent and low-dose drug administration compared with conventional therapy, which was first experimented previously with positive results for patients with metastatic breast and recurrent ovarian cancer, advanced multiple myeloma and other types of carcinomas $(47,48)$. The metronomic use of ZOL was found to be effective in inhibiting tumor growth and metastasis to lung and liver in both of primary and metastatic breast cancer (20). The present study results reveal that metronomic $\mathrm{ZOL}$ was effective in decreasing tumor burden, inhibiting metastasis to lung and inhibiting osteolysis in 4T1 mouse carcinoma. In addition, the combination of metronomic CS and ZOL shows the most potent antitumor and antimetastasis effects among the three groups. Such findings reveal promising results of metronomic ZOL in clinical trials, and may play influential roles in the future production of CS as a supplement in breast cancer treatment with ZOL.

Based on results of the present study, more detailed molecular mechanisms, for instance, genomic and proteomic responses on antimetastasis and anti-osteolysis should be studied. Further investigation is needed to determine the clinical efficacy and safety of the combination therapy of CS and metronomic ZOL in human subjects with breast cancer metastasis. Our observations revealed promising results in breast cancer treatment of the combined use of herbal medicine CS and metronomic ZOL, suggesting the promising application in breast cancer patients clinically.

\section{Acknowledgements}

This study was supported by the Focused Innovations Scheme (Major Area Scheme A, Phase 2) of The Chinese University of Hong Kong. The authors would like to thank Dr Sammy Siu and Ms. Anita Shum for their technical support on the micro-CT analysis.

\section{References}

1. Hara Y: Advances in Food Science and Technology. In: Nippon Shokuhin Kogyo Gakkai. Korin, Tokyo, 1990.

2. Kuriyama S, Shimazu T, Ohmori K, Kikuchi N, Nakaya N, Nishino Y, Tsubono Y and Tsuji I: Green tea consumption and mortality due to cardiovascular disease, cancer, and all causes in Japan: The Ohsaki study. JAMA 296: 1255-1265, 2006

3. Shixian Q, VanCrey B, Shi J, Kakuda Y and Jiang Y: Green tea extract thermogenesis-induced weight loss by epigallocatechin gallate inhibition of catechol-O-methyltransferase. J Med Food 9: 451-458, 2006.

4. Nakazato T, Ito K, Miyakawa Y, Kinjo K, Yamada T, Hozumi N, Ikeda Y and Kizaki M: Catechin, a green tea component, rapidly induces apoptosis of myeloid leukemic cells via modulation of reactive oxygen species production in vitro and inhibits tumor growth in vivo. Haematologica 90: 317-325, 2005.

5. Bettuzzi S, Brausi M, Rizzi F, Castagnetti G, Peracchia G and Corti A: Chemoprevention of human prostate cancer by oral administration of green tea catechins in volunteers with high-grade prostate intraepithelial neoplasia: A preliminary report from a one-year proof-of-principle study. Cancer Res 66: 1234-1240, 2006

6. Gu JW, Makey KL, Tucker KB, Chinchar E, Mao X, Pei I, Thomas EY and Miele L: EGCG, a major green tea catechin suppresses breast tumor angiogenesis and growth via inhibiting the activation of HIF-1 $\alpha$ and $\mathrm{NF} \kappa \mathrm{B}$, and VEGF expression. Vasc Cell 5: 9, 2013.

7. Lecumberri E, Dupertuis YM, Miralbell R and Pichard C: Green tea polyphenol epigallocatechin-3-gallate (EGCG) as adjuvant in cancer therapy. Clin Nutr 32: 894-903, 2013.

8. Qiao J, Gu C, Shang W, Du J, Yin W, Zhu M, Wang W, Han M and Lu W: Effect of green tea on pharmacokinetics of 5-fluorouracil in rats and pharmacodynamics in human cell lines in vitro. Food Chem Toxicol 49: 1410-1415, 2011.

9. Liang G, Tang A, Lin X, Li L, Zhang S, Huang Z, Tang H and Li QQ: Green tea catechins augment the antitumor activity of doxorubicin in an in vivo mouse model for chemoresistant liver cancer. Int J Oncol 37: 111-123, 2010.

10. Farabegoli F, Papi A and Orlandi M: (-)-Epigallocatechin-3gallate down-regulates EGFR, MMP-2, MMP-9 and EMMPRIN and inhibits the invasion of MCF-7 tamoxifen-resistant cells. Biosci Rep 31: 99-108, 2011.

11. Luo KW, Ko CH, Yue GGL, Lee JKM, Li KK, Lee M, Li G, Fung KP, Leung PC and Lau CB: Green tea (Camellia sinensis) extract inhibits both the metastasis and osteolytic components of mammary cancer 4T1 lesions in mice. J Nutr Biochem 25: 395-403, 2014.

12. Labrinidis A, Hay S, Liapis V, Findlay DM and Evdokiou A: Zoledronic acid protects against osteosarcoma-induced bone destruction but lacks efficacy against pulmonary metastases in a syngeneic rat model. Int J Cancer 127: 345-354, 2010.

13. Senaratne SG and Colston KW: Direct effects of bisphosphonates on breast cancer cells. Breast Cancer Res 4: 18-23, 2002.

14. Evdokiou A,Labrinidis A, Bouralexis S, Hay S and Findlay DM: Induction of cell death of human osteogenic sarcoma cells by zoledronic acid resembles anoikis. Bone 33: 216-228, 2003.

15. Wood J, Bonjean K, Ruetz S, Bellahcène A, Devy L, Foidart JM, Castronovo V and Green JR: Novel antiangiogenic effects of the bisphosphonate compound zoledronic acid. J Pharmacol Exp Ther 302: 1055-1061, 2002. 
16. Zhao X, Xu X, Guo L, et al: Biomarker alterations with metronomic use of low-dose zoledronic acid for breast cancer patients with bone metastases and potential clinical significance. Breast Cancer Res Treat 124: 733-743, 2010.

17. Zhao X, Xu X, Zhang Q, Jia Z, Sun S, Zhang J, Wang B, Wang Z and $\mathrm{Hu} \mathrm{X}$ : Prognostic and predictive value of clinical and biochemical factors in breast cancer patients with bone metastases receiving 'metronomic' zoledronic acid. BMC Cancer 11: 403, 2011.

18. Daubiné F, Le Gall C, Gasser J, Green J and Clézardin P: Antitumor effects of clinical dosing regimens of bisphosphonates in experimental breast cancer bone metastasis. J Natl Cancer Inst 99: 322-330, 2007.

19. Facchini G, Caraglia M, Morabito A, et al: Metronomic administration of zoledronic acid and taxotere combination in castration resistant prostate cancer patients: Phase I ZANTE trial. Cancer Biol Ther 10: 543-548, 2010.

20. Luo KW, Ko CH, Yue GGL, et al: Anti-tumor and anti-osteolysis effects of the metronomic use of zoledronic acid in primary and metastatic breast cancer mouse models. Cancer Lett 339: 42-48, 2013.

21. Peng L, Song XH, Shi XG, Li JX and Ye CX: An improved HPLC method for simultaneous determination of phenolic compounds, purine alkaloids and theanine in Camellia species. J Food Compos Anal 21: 559-563, 2008.

22. Staibano S, Lo Muzio L, Mezza E, Argenziano G, Tornillo L, Pannone $G$ and De Rosa G: Prognostic value of apoptotic index in cutaneous basal cell carcinomas of head and neck. Oral Oncol 35: 541-547, 1999.

23. Vigl B, Zgraggen C, Rehman N, Banziger-Tobler NE, Detmar M and Halin C: Coxsackie- and adenovirus receptor (CAR) is expressed in lymphatic vessels in human skin and affects lymphatic endothelial cell function in vitro. Exp Cell Res 315 336-347, 2009

24. Xiao D and Singh SV: Phenethyl isothiocyanate inhibits angiogenesis in vitro and ex vivo. Cancer Res 67: 2239-2246, 2007.

25. Azim HA, Kamal NS and Azim HA Jr: Bone metastasis in breast cancer: The story of RANK-ligand. J Egypt Natl Cancer Inst 24: 107-114, 2012

26. Chaudhary AK, Pandya S, Ghosh K and Nadkarni A: Matrix metalloproteinase and its drug targets therapy in solid and hematological malignancies: An overview. Mutat Res 753: 7-23, 2013.

27. Fitzgerald JB, Schoeberl B, Nielsen UB and Sorger PK: Systems biology and combination therapy in the quest for clinical efficacy. Nat Chem Biol 2: 458-466, 2006.

28. Yeh $\mathrm{P}$ and Kishony R: Networks from drug-drug surfaces. Mol Syst Biol 3: 85, 2007.

29. Lam YC, Cheng CW, Peng H, Law CK, Huang $X$ and Bian $Z$ : Cancer patients' attitudes towards Chinese medicine: A Hong Kong survey. Chin Med 4: 25, 2009

30. Wang JA, Zhou FX and Zhang ML: Treatment for advanced gastric cardia carcinoma in 26 cases of integrated traditional Chinese and Western Medicine. Shanxi. J Tradit Chin Med 25 772-773, 2004.

31. Eliza WL, Fai CK and Chung LP: Efficacy of Yun Zhi (Coriolus versicolor) on survival in cancer patients: Systematic review and meta-analysis. Recent Pat Inflamm Allergy Drug Discov 6 : 78-87, 2012.

32. Mazumder ME, Beale P, Chan C, Yu JQ and Huq F: Epigallocatechin gallate acts synergistically in combination with cisplatin and designed trans-palladiums in ovarian cancer cells. Anticancer Res 32: 4851-4860, 2012.
33. Jackman AL, Kaye S and Workman P: The combination of cytotoxic and molecularly targeted therapies - can it be done. Drug Discov Today 1: 445-454, 2004.

34. Pulaski BA and Ostrand-Rosenberg S: Reduction of established spontaneous mammary carcinoma metastases following immunotherapy with major histocompatibility complex class II and B7.1 cell-based tumor vaccines. Cancer Res 58: 1486-1493, 1998.

35. Kerr JF, Wyllie AH and Currie AR: Apoptosis: A basic biological phenomenon with wide-ranging implications in tissue kinetics. Br J Cancer 26: 239-257, 1972.

36. Baliga MS, Meleth S and Katiyar SK: Growth inhibitory and antimetastatic effect of green tea polyphenols on metastasisspecific mouse mammary carcinoma 4T1 cells in vitro and in vivo systems. Clin Cancer Res 11: 1918-1927, 2005.

37. Ko CH, Lau KM, Choy WY and Leung PC: Effects of tea catechins, epigallocatechin, gallocatechin, and gallocatechin gallate, on bone metabolism. J Agric Food Chem 57: 7293-7297, 2009.

38. Lee JH, Jin H, Shim HE, Kim HN, Ha H and Lee ZH: Epigallocatechin-3-gallate inhibits osteoclastogenesis by down-regulating c-Fos expression and suppressing the nuclear factor-kappaB signal. Mol Pharmacol 77: 17-25, 2010.

39. Lee SH, Kim BJ, Choi HJ, et al: (-)-Epigallocathechin-3-gallate, an AMPK activator, decreases ovariectomy-induced bone loss by suppression of bone resorption. Calcif Tissue Int 90: 404-410, 2012.

40. Deeks ED and Perry CM: Zoledronic acid: A review of its use in the treatment of osteoporosis. Drugs Aging 25: 963-986, 2008.

41. Zhang FL and Casey PJ: Protein prenylation: Molecular mechanisms and functional consequences. Annu Rev Biochem 65: 241-269, 1996.

42. Tobiume H, Kanzaki S, Hida S, Ono T, Moriwake T, Yamauchi S, Tanaka $\mathrm{H}$ and Seino Y: Serum bone alkaline phosphatase isoenzyme levels in normal children and children with growth hormone $(\mathrm{GH})$ deficiency: A potential marker for bone formation and response to GH therapy. J Clin Endocrinol Metab 82: 2056-2061, 1997.

43. Rachner TD, Singh SK, Schoppet M, Benad P, Bornhäuser M, Ellenrieder V, Ebert R, Jakob F and Hofbauer LC: Zoledronic acid induces apoptosis and changes the TRAIL/OPG ratio in breast cancer cells. Cancer Lett 287: 109-116, 2010.

44. Zhou F, Zhou H, Wang T, Mu Y, Wu B, Guo DL, Zhang XM and $\mathrm{Wu} \mathrm{Y}$ : Epigallocatechin-3-gallate inhibits proliferation and migration of human colon cancer SW620 cells in vitro. Acta Pharmacol Sin 33: 120-126, 2012.

45. Oppenheimer SB: Cellular basis of cancer metastasis: A review of fundamentals and new advances. Acta Histochem 108: 327-334, 2006.

46. Hiraga T, Williams PJ, Ueda A, Tamura D and Yoneda T: Zoledronic acid inhibits visceral metastases in the 4T1/luc mouse breast cancer model. Clin Cancer Res 10: 4559-4567, 2004.

47. Orlando L, Cardillo A, Ghisini R, Rocca A, Balduzzi A, Torrisi R, Peruzzotti G, Goldhirsch A, Pietri E and Colleoni M: Trastuzumab in combination with metronomic cyclophosphamide and methotrexate in patients with HER-2 positive metastatic breast cancer. BMC Cancer 6: 225, 2006.

48. de Weerdt O, van de Donk NW, Veth G, Bloem AC, Hagenbeek A and Lokhorst HM: Continuous low-dose cyclophosphamideprednisone is effective and well tolerated in patients with advanced multiple myeloma. Neth J Med 59: 50-56, 2001. 